\section{Education of psychiatric nurses}

\section{DeAR Sirs}

For sometime many psychiatrists have been concerned about developments in nursing practice and nurse training. These issues have been clearly set out by Michael Jorsh (1991). He describes the growing independence of psychiatric nursing from psychiatrists, the lack of involvement of psychiatrists in nurse education and the failure of nurse training to emphasise the importance of basic psychiatry, psychiatric syndromes and psychopathology. He goes on to describe how matters are likely to get worse with the introduction of Project 2000.

This is a very serious and regrettable development and we are very grateful to Dr Jorsh for drawing our attention to it. In Wales an attempt is made to redress the balance in two ways:

(a) The Welsh National Board of Nursing (being the regulatory body for nurse training in Wales) is being alerted to the concern of psychiatrists about this matter. Recently its Mental Health Committee has established its programme of work for 1991/92/93 which includes a review of psychiatric nurse training in terms of basic psychiatry, psychiatric syndromes and drug treatment in relation to Project 2000.

(b) In the Psychogeriatric Department of this hospital, the Weed system of Problem Orientated Medical Records has been used since 1976. With the introduction of the Nursing Process, it did seem inappropriate for the two key groups of a multidisciplinary team to use separate and yet identical systems of working. As a result, for the last five years we have used a Unified Approach (Williams \& Owen, 1988) where all the members of the multidisciplinary team use one set of problems and develop joint care plans. Department notes have been abandoned and the medical notes have now become the patient's file which is used by every member of the team. One further advantage of this approach is that the traditional psychiatric concepts are used in the day to day management of patients. In this way it plays an important part in teaching nurses basic psychiatry, psychiatric syndromes and psychopathology.

Cefn Coed Hospital

D. D. R. WILLIAMS

Swansea SA2 OGH

\section{References}

JoRSH, M. S. (1991) The changes in the education of psychiatric nurses. Do psychiatrists have a role? Psychiatric Bulletin, 15, 339-340.
Williams, D. D. R. \& Owen, A. (1988) Re-establishing effective team work. Health Trends, November, 20, 129-130.

\section{Being a control}

\section{DeAr Sirs}

What do you usually say to a patient who asks in regard to the medication you are prescribing, "How would you like to try some?" You can smile benignly and say that you would take it if you felt unwell, or you could say that you do not have to take it to know that it is an appropriate prescription for someone else, or you can do your best to emphathise and visualise yourself experiencing some of the side effects the patient is complaining of.

Occasionally in life one is given the opportunity to take empathy on this topic one step further. If you happen to be a new recruit in a research project that requires control subjects you can take the plunge from the role of empathic reassuring research clinician to that of anxious and uneasy research subject.

It was thus I was immersed as a voluntary control in our current research project on the Psychobiology of Suicidal Behaviour. One of the indices being examined is the prolactin response to the serotonergic agonist fenfluramine. Of course control subjects are necessary, and difficult to recruit. I had not stopped to wonder why. I passed the Non-Patient version of the Personality Disorder Examination and the Structured Clinical Interview for DSM-III-R with relief and got the all clear for the "fen. challenge". I am not a great person for breakfast, but no one has ever told me not to have breakfast, or that I would have to miss lunch. It never seemed like a big deal for me to tell patients that they would not be eating until 2-3 pm. It sometimes, I must admit, might even have seemed in retrospect like a throwaway line on the way out the door, "Oh, and by the way you will be starving for us". So I did not eat breakfast. I dutifully booked in at $7.45 \mathrm{a} . \mathrm{m}$. like a sheep - an anxious sheep who had not slept too well the previous night. I scored for anxiety on the Brief Psychiatric Rating Scale and on the Hamilton Rating Scale.

I have good veins, usually. But why is it that doctors make such bad patients? The research nurse, competent, and experienced with all sorts of veins, seemed hesitant - antecubital fossa or forearm. She does not usually query this choice but she did with me. Why? Was it the way I rolled up my sleeve? I purposely did not direct her. She knew I was nervous. The forearm intravenous (IV) line would give me more mobility. So that is where it went, and it was painful. No complaints and on with the study. A white-coated laboratory technician appeared with his colleague and whisked my platelets away as soon as they were drawn. 
At $9.15 \mathrm{am}$ I took $60 \mathrm{mg}$ of fenfluramine and sat back to see what would happen. Hourly measurements of vital signs, mood, alertness and anxiety were recorded along with hourly blood draws for cortisol and prolactin response. My blood pressure, pulse and body temperature dropped considerably. I felt less anxious, quite relaxed in fact. About two hours post-medication I gradually felt what I can describe as feelings of depersonalisation. I felt as if I was outside myself looking in on this experiment. These feelings only lasted a couple of minutes and then I was back to myself again. Six hours postmedication, I had not experienced many of the expected side effects. The intravenous line was discontinued having been resited three hours into the experiment into an antecubital vein, and I was free to go. I had been the guinea pig, put myself in the patient's shoes, experienced what it was like to "try some yourself" for the benefit of science. I had experienced nausea, dry mouth, and anorexia. Other effects of the serotonergic surge will become apparent in the blood results. I felt exhausted and it took me at least 24 hours to get back to normal. Squeamish colleagues were horrified at what I had done to myself as they tried to look the other way when I wended my way to the bathroom past them with my IV stand in tow.

I cannot say it was fun. It was an experience. It reminded this researcher of the importance of empathising with patients when prescribing medication with known side effects, even if they are mild, and being grateful to patients who take part in research studies such as ours in particular, and research studies in general.

Western Psychiatric institute and Clinic 3811 O'Hara Street, Pittsburgh, PA, USA

Supported by Fogarty International Award 1 F05 TW0453801. Department of Health and Human Services, National Institute of Mental Health, Bethesda, Maryland 20892.

\section{What would you have done?}

\section{DeAR Sirs}

S.T. is a 68-year-old married lady with admissions to our psychiatric hospital in the past 34 years. She has been diagnosed as suffering from schizophrenia but in later admissions has also displayed prominent depressive symptoms. She has no insight into her illness and is currently resident on a long stay ward.

Recently she was noted to be weak and pale. Examination revealed a mass in her pelvic region which X-ray showed to be bladder calculus. She suffered from recurrent urinary tract infection and is in intermittent pain. The surgical opinion is that the calculus requires open cystotomy for removal but the patient refused operation. Her haemoglobin level dropped to $8.2 \mathrm{~g} / \mathrm{dl}$ and she was given 2 units of blood with marked improvement.

Mentally she is bright, cheerful and fully mobile. She said she felt well and did not admit to delusions of persecution or auditory halucinations. But she did not know her age or the year, month, season or day. She knew her name, and her husband's name, but not the name of the place or that she was in a hospital. On specific questioning about a bladder stone she denied having been told of its presence or of having had any pain from it. When told of its presence again, and the need for operation to remove it, she replied "I don't believe in operation when one does not want operation."

She is not currently in pain (on analgesics) but has to have regular haemoglobin estimations. She refuses to have operation and has little insight into the need for surgery. Surgical opinion is that it would be an assault to go ahead with surgery without her consent. We would appreciate suggestions on management.

Glanrhyd \& Penyfai Hospitals

J. P. JOYCE

S. S. PALIA

Bridgend, Mid Glamorgan

CF31 4LN 